\title{
Dynamics of Peptide Bonds: A Study of N-Acetylethanolamine Using Chirped-Pulsed Fourier Transform Microwave Spectroscopy
}

\author{
JOSIAH R. BAILEY, TIMOTHY J. MCMAHON, and RYAN G. BIRD* \\ Department of Chemistry, University of Pittsburgh Johnstown, Johnstown, PA 15904 \\ *Email:rbird@pitt.edu
}

\begin{abstract}
.
The torsional barrier of a methyl rotor can be used to probe the local electronic environment around the group to which it is attached. In this study, the microwave spectrum of the amide-containing $\mathrm{N}$-acetylethanolamine was recorded in a pulsed supersonic jet using chirped pulse techniques. The spectrum displays both ${ }^{14} \mathrm{~N}$ quadrupole and methyl torsional splittings, with the barrier height determined to be $96.05 \mathrm{~cm}^{-1}$. Comparisons of this barrier to those of similar molecules illustrate the effects of methyl group substitution on the distribution of $\pi$-electrons within the amide bond.
\end{abstract}

Keywords: internal rotation; microwave spectrum; tunneling splittings; amide bond; acetamide 


\section{Introduction.}

Amide bonds are prevalent in both the synthetic and natural world. They play important roles in the strength and flexibility of materials such as nylon and Kevlar. They are most commonly found as linking bonds in the backbone units of peptides, affecting both the stability and the structural shape as peptides fold into proteins. Additionally, amide bonds are found in pharmaceuticals, hormones, and other metabolites, making them one of the more important types of chemical bonds encountered in our everyday lives. Thus, a study of the chemical nature of these peptide bonds will lead to a better understanding of how proteins fold, how they bind to substrates, and how biochemical reactions are influenced by these interactions.

A typical amide bond exists in one of two possible resonance structures, shown in Scheme 1. ${ }^{1}$ Empirical evidence for the existence of both of these resonance structures is overwhelming. Amide bonds display a longer C-O bond length than normally observed in most aldehydes and a shorter $\mathrm{C}-\mathrm{N}$ bond length than in most amines. ${ }^{2-10}$ Additionally, amide bonds are stabilized through $n_{\mathrm{N}} \rightarrow \pi_{\mathrm{C}=0}^{*}$ electron delocalization, with barriers to rotation about the C-N bond of around $7000 \mathrm{~cm}^{-1} .11$ This rigidity of amide bonds further adds to the stability of protein backbones.

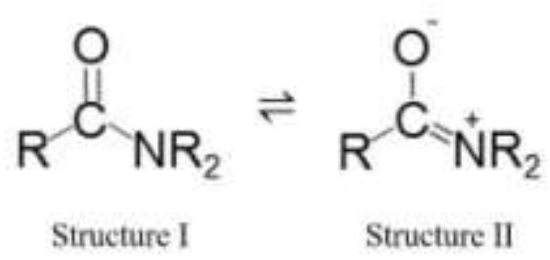

Scheme 1. Resonance forms describing the electronic structure around amide bonds 
One way to explore the extent of this delocalization is through an investigation of the torsional barrier of methyl groups attached to amide groups. ${ }^{12}$ One class of chemicals, known as acetamides, contains a methyl group attached to the carbonyl of the amide group. Currently, several such acetamides have been studied by the Stahl group, ${ }^{13,14}$ Ohashi et al., ${ }^{15,16}$ and Suenram et al. ${ }^{17}$ Here, we examine how substitutions at the nitrogen atom affect the methyl-rotor barrier and the electronic environment around the amide bond by studying $\mathrm{N}$-acetylethanolamine.

\section{Experimental.}

$\mathrm{N}$-acetylethanolamine (AEA), also known as $\mathrm{N}$-(2-hydroxyethyl)acetamide, was purchased from Aldrich and used without further purification. Chirped-pulse Fourier transform microwave (CP-FTMW) data were obtained using a modified spectrometer that resembles the instrument developed by the Pate group,${ }^{18}$ but utilizes a mirror-horn cavity to reduce the power requirements while retaining some of the broadband capabilities of the original machine. ${ }^{19}$ Liquid AEA was placed in an internal sample container, heated to $40^{\circ} \mathrm{C}$, entrained in 1 bar of $\mathrm{He}$, and then expanded perpendicular to the microwave axis. Spectra of AEA were taken between 6.5 and $17.5 \mathrm{GHz}$ in $450 \mathrm{MHz}$ segments, collecting a $10 \mu$ s free-induction decay (FID) and signal averaging for up to 10,000 shots in each segment. Theoretical calculations were performed using the Gaussian 09 suite of electronic structure programs. ${ }^{20}$

\section{$\underline{\text { Result. }}$}

Figure 1 shows the structure of the two lowest energy conformations of AEA. As can be seen, both conformations have intramolecular interactions originating from the hydroxyl group. Conformer I has a hydrogen bond between the hydroxyl group and the carbonyl group, while in conformer II the $\mathrm{OH}$ group interacts with the lone pair on the nitrogen. In both cases, the attached $\mathrm{CH}_{3}$ group is anti to the $\mathrm{C}=\mathrm{O}$ double bond. Table 1 lists the molecular parameters of 
both conformers. Conformer I has the lower energy by $4.25 \mathrm{~kJ} / \mathrm{mol}$. The largest differences predicted between the conformers are in the rotational constant $B$, the quadrupole coupling terms, the barrier height and the positioning of the methyl rotor axis. Estimates of the angle between the rotor axis and the $a$ inertial axis, $\delta$, and the angle between the rotor axis and $a-b$ plane, $\varepsilon$, were calculated using direction cosines and the Gaussian predicted structures. Quadrupole constants were calculated using the b3pw91/6-311+g(df,pd) level of theory and Bailey's calibration coefficient, ${ }^{21} 4.5586 \mathrm{MHz}$ a.u. ${ }^{-1}$.

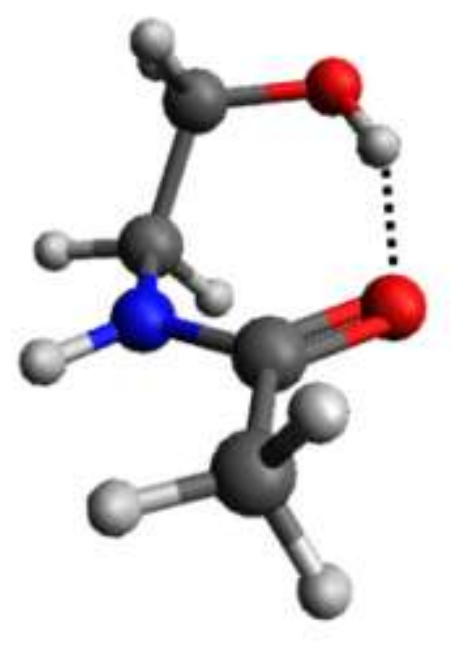

Conformer I

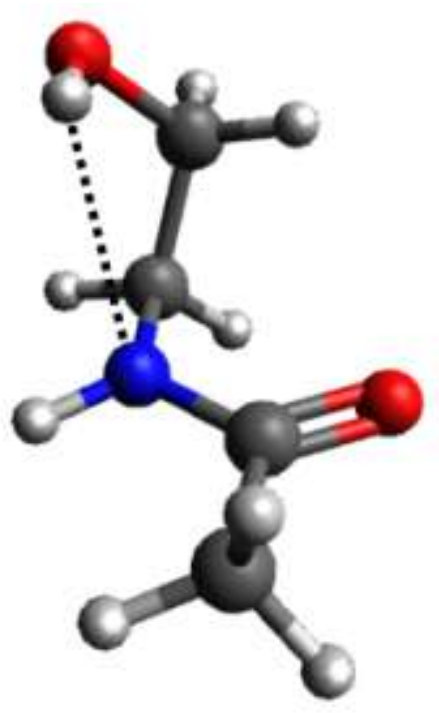

Conformer II

Figure 1. The two lowest energy conformations of AEA with both displaying intramolecular hydrogen bonds. 
Table 1. Theoretical Parameters for the Two Lowest Conformers of AEA

\begin{tabular}{|l|l|l|}
\hline Parameter & Conformer 1 & Conformer 2 \\
\hline $\mathrm{A}(\mathrm{MHz})$ & $5095.447^{\mathrm{a}}$ & $5112.521^{\mathrm{a}}$ \\
\hline $\mathrm{B}(\mathrm{MHz})$ & $1732.869^{\mathrm{a}}$ & $1477.478^{\mathrm{a}}$ \\
\hline $\mathrm{C}(\mathrm{MHz})$ & $1399.771^{\mathrm{a}}$ & $1377.928^{\mathrm{a}}$ \\
\hline$\chi_{\mathrm{aa}}(\mathrm{MHz})$ & $1.61^{\mathrm{b}}$ & $-1.02^{\mathrm{b}}$ \\
\hline$\chi_{\mathrm{bb}}(\mathrm{MHz})$ & $1.66^{\mathrm{b}}$ & $-0.89^{\mathrm{b}}$ \\
\hline$\chi_{c \mathrm{cc}}(\mathrm{MHz})$ & $-3.27^{\mathrm{b}}$ & $1.91^{\mathrm{b}}$ \\
\hline$\delta(\mathrm{deg})$ & $15.0^{\mathrm{c}}$ & $36.5^{\mathrm{c}}$ \\
\hline$\varepsilon(\mathrm{deg})$ & $84.7^{\mathrm{c}}$ & $53.8^{\mathrm{c}}$ \\
\hline $\mathrm{V}_{3}\left(\mathrm{~cm}^{-1}\right)$ & $122.9^{\mathrm{d}}$ & $90.11^{\mathrm{d}}$ \\
\hline Relative Energy $(\mathrm{kJ} / \mathrm{mol})$ & 0.00 & 4.26 \\
\hline
\end{tabular}

${ }^{\mathrm{a}}$ Calculated using Gaussian mp2/6-311+G(d,p)

${ }^{\mathrm{b}}$ Calculated from the optimized structure using Gaussian b3pw91/6-311+g(df,pd)

${ }^{\mathrm{c}}$ Determined from the optimized structure

${ }^{\mathrm{d}}$ Calculated using Gaussian mp2/6-311+G(2d,p)

${ }^{\mathrm{e}}$ Calculated from the optimized structure using Gaussian mp2/6-311+G(d,p)

The microwave spectrum of AEA from 7 to $18 \mathrm{GHz}$, consisting of both $\mu_{\mathrm{a}^{-}}$and $\mu_{\mathrm{b}}$-type R-branch transitions, is shown in Figure 2a. Two sets of splittings were observed, one from the quadrupole coupling of the nitrogen and the other from the torsional motions of the methyl rotor. These are shown in greater detail in Fig. 2b. Transitions from the rigid-rotor A-band were originally fit using $\mathrm{JB}^{2} 5^{22}$ and then used in $\mathrm{XIAM}^{23}$ to assign the $E$-band and determine the global fit. The observed methyl rotor barrier for AEA was determined to be $96.05 \mathrm{~cm}^{-1}$, and the angles $\delta$ and $\varepsilon$ were determined to be 16.2 degrees and 80.1 degrees, respectively. Experimental parameters from this global fit are listed in Table 2 and exhibit good agreement with the ab initio calculations for conformer I. Although the $A, C$, and $\mathrm{V}_{3}$ parameters of conformers I and II are quite similar, the rotational constant $B$, the quadrupole coupling terms, and the methyl rotor angles clearly distinguish I from II. Thus experimental evidence confirms that $\mathbf{I}$ is the most stable conformer of AEA. 


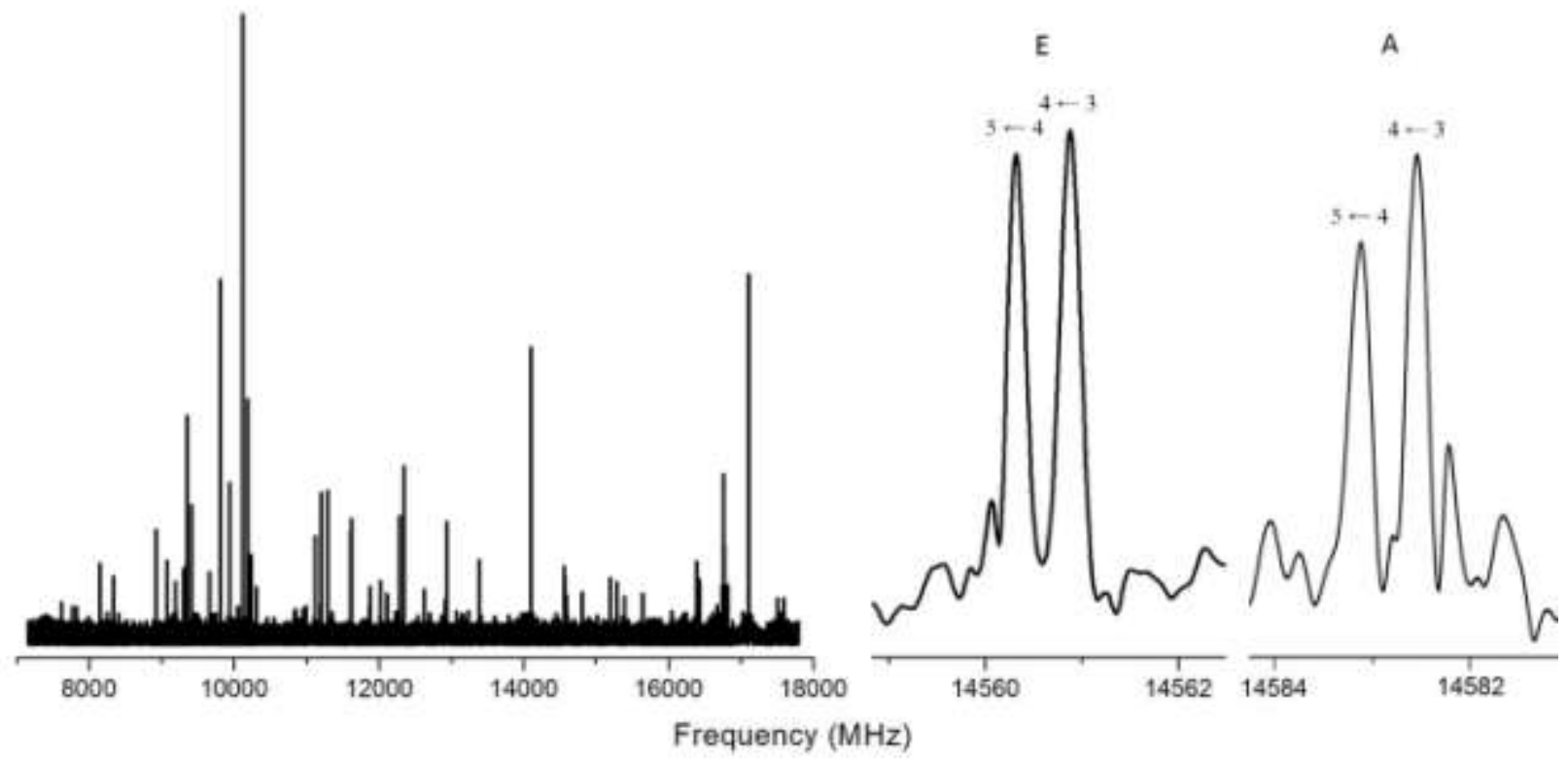

Figure 2. (Left) The microwave spectrum of AEA from 6.5 to $17.5 \mathrm{GHz}$. (Right) The hyperfine splittings for both torsional subbands of the $4_{14} \leftarrow 3_{03}$ transition.

Table 2: Experimental Parameters for AEA

\begin{tabular}{|l|l|l|}
\hline Parameter & Experimental & Theoretical \\
\hline $\mathrm{A}(\mathrm{MHz})$ & $5072.85(1)$ & $5095.447^{\mathrm{a}}$ \\
\hline $\mathrm{B}(\mathrm{MHz})$ & $1728.516(5)$ & $1732.869^{\mathrm{a}}$ \\
\hline $\mathrm{C}(\mathrm{MHz})$ & $1409.371(3)$ & $1399.771^{\mathrm{a}}$ \\
\hline$\chi_{\mathrm{aa}}(\mathrm{MHz})$ & $1.56(7)$ & $1.61^{\mathrm{b}}$ \\
\hline$\chi_{\mathrm{bb}}(\mathrm{MHz})$ & $1.51(3)$ & $1.66^{\mathrm{b}}$ \\
\hline$\chi_{\mathrm{cc}}(\mathrm{MHz})$ & $-3.07(9)$ & $-3.27^{\mathrm{b}}$ \\
\hline$\delta(\mathrm{deg})$ & $16.18(3)$ & $15.0^{\mathrm{c}}$ \\
\hline$\varepsilon(\mathrm{deg})$ & $80.1(7)$ & $84.7^{\mathrm{c}}$ \\
\hline $\mathrm{V}_{3}\left(\mathrm{~cm}^{-1}\right)$ & $96.05(1)$ & $122.9^{\mathrm{d}}$ \\
\hline$\Delta \mathrm{I}\left(\mathrm{u} \AA^{2}\right)$ & -33.42 & -29.78 \\
\hline $\mathrm{N}$ lines & 66 & \\
\hline
\end{tabular}

${ }^{\mathrm{a}}$ Calculated using Gaussian mp2/6-311+G(d,p)

${ }^{\mathrm{b}}$ Calculated from the optimized structure using Gaussian b3pw91/6-311+g(df,pd)

${ }^{c}$ Determined from the optimized structure

${ }^{\mathrm{d}}$ Calculated using Gaussian mp2/6-311+G(2d,p) 


\section{Discussion.}

Listed in Table 3 are the measured three-fold barrier heights that govern the restricted internal rotation of carbonyl methyl groups in several different molecules containing the acetamide group. These range from $\mathrm{V}_{3}=-24.34 \mathrm{~cm}^{-1}$ in acetamide itself ${ }^{17}$ to +517.04 and $+619.48 \mathrm{~cm}^{-1}$ in two conformers of the doubly substituted diethylacetamide. ${ }^{16}$ (Positive barrier heights indicate that the methyl group is in the syn configuration, while negative values are associated with anti.) The barrier for AEA $\left(-96.05 \mathrm{~cm}^{-1}\right)$ is intermediate between these, and comparable to the barriers of the monosubstituted methylacetamide $\left(-73.47 \mathrm{~cm}^{-1}\right)^{15}$ and ethylacetamide $\left(-73.48 \mathrm{~cm}^{-1}\right) .{ }^{14}$ Clearly, the magnitude and the sign of this barrier is extremely sensitive to substitution of the terminal nitrogen atom in the peptide bond.

Table 3. Observed Barriers ${ }^{a}$ to Internal Rotation of the Carbonyl Carbon Methyl Group in Six Acetamides

\begin{tabular}{|c|c|c|c|c|c|}
\hline \multicolumn{2}{|c|}{ Unsubstituted } & \multicolumn{2}{|c|}{ Mono-substituted } & \multicolumn{2}{|c|}{ Di-substituted } \\
\hline \multicolumn{2}{|c|}{ Compound $\quad V_{3}\left(\mathrm{~cm}^{-1}\right)$} & \multicolumn{2}{|c|}{ Compound $\quad V_{3}\left(\mathrm{~cm}^{-1}\right)$} & \multicolumn{2}{|c|}{ Compound $\quad V_{3}\left(\mathrm{~cm}^{-1}\right)$} \\
\hline \multirow{3}{*}{ Acetamide } & -24.34 & Methylacetamide & -73.47 & Diethylacetamide (I) & +517.04 \\
\hline & & Ethylacetamide & -73.48 & Diethylacetamide (II) & +619.48 \\
\hline & & AEA & -96.05 & & \\
\hline
\end{tabular}

${ }^{a}$ Positive $\mathrm{V}_{3}$ barrier heights indicate the methyl group is in a syn configuration with respect to the $\mathrm{C}=\mathrm{O}$ double bond, while negative values are associated with anti.

Insights into the factors that are responsible for these trends have been discussed by several authors. (An excellent review may be found in Ref. 24). The barrier to methyl group rotation in simple $\pi$-bonded molecules like propene $\left(\mathrm{CH}_{3}-\mathrm{CH}=\mathrm{CH}_{2}\right)$ and acetaldehyde $\left(\mathrm{CH}_{3}-\mathrm{CH}=\mathrm{O}\right)$ may be understood by considering the four interactions between the $\pi$ and $\pi^{*}$ orbitals of the methyl group and the corresponding orbitals of the double bond. In these molecules, the repulsive overlap between occupied $\left(\pi_{\text {methyl }}\right.$ and $\left.\pi_{\text {double-bond }}\right)$ is greater in the staggered ( $\underline{\text { anti) }}$ ) conformation than in the eclipsed ( $\underline{\operatorname{syn}})$ one, whereas the reverse is true for the 
unoccupied $\pi^{*}$ orbitals. Hence, the syn conformer is preferred in both propene and acetaldehyde. However, this conformational preference is reduced in acetaldehyde, owing to replacement of the terminal $=\mathrm{CH}_{2}$ group with the more electronegative oxygen atom .

Replacement of the aldehyde hydrogen with the $\mathrm{NH}_{2}$ group in $\mathrm{CH}_{3}-\mathrm{CO}-\mathrm{NH}_{2}$ introduces another set of orbitals, particularly the orbital containing the lone pair. This $n_{\mathrm{N}}$ orbital creates a repulsive overlap with the $\pi_{\text {methyl }}$ orbitals, significantly destabilizing the syn position, and resulting in the anti conformation displayed in Figure 3. This "stabilization" of the anti position decreases the energy difference between the two conformations, thus reducing the barrier to methyl rotation. Therefore, both the preferred conformation and the torsional barrier of the methyl group depends on the non-bonding electron density around the nitrogen.

Acetaldehyde

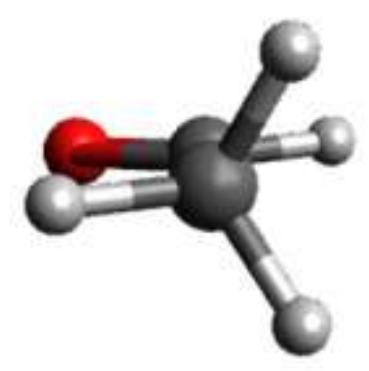

Low Barrier

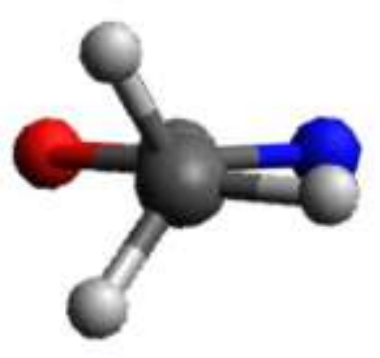

High Barrier

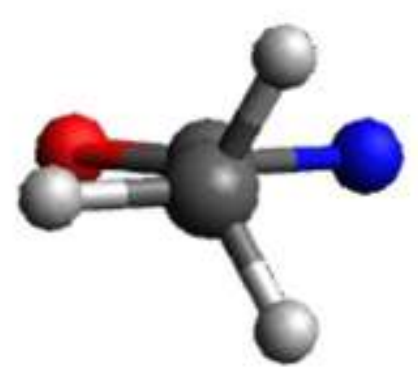

Figure 3. The position of the methyl group with respect to the $\mathrm{C}=\mathrm{O}$ double bond for acetaldehyde and for the acetamide molecules having both low and high torsional barriers.

Recent studies ${ }^{12}$ on amide containing molecules have shown that as the torsional barrier increases, the amount of $\mathrm{C}-\mathrm{N}$ double bond character increases (and $\mathrm{C}-\mathrm{O}$ double bond character decreases), which eventually leads to a switch back to the syn conformation (Figure 3). The principal orbital interaction that is responsible for this effect is $n_{\mathrm{N}} \rightarrow \pi^{*} \mathrm{C}=\mathrm{O}$ delocalization, which reduces the $\mathrm{n}_{\mathrm{N}}$ electron density, reducing the destabilizing effect on the syn position. Substitution 
of the $\mathrm{NH}_{2}$ hydrogens with electron-donating groups like $\mathrm{CH}_{3}$ and $\mathrm{C}_{2} \mathrm{H}_{5}$ further enhances this effect, nicely accounting for the trends evident in Table 3. One small anomaly occurs when comparing AEA with ethylacetamide (EAA), which differs by the replacement of a $\mathrm{CH}_{3}$ hydrogen with an $\mathrm{OH}$ group. Its 3-fold (carbonyl) methyl barrier is $\sim 20 \mathrm{~cm}^{-1}$ higher than that in EAA, showing a remarkable effect for a substitution four atoms away from the rotor. The hydroxyl group in AEA is linked to the carbonyl oxygen by a hydrogen bond, leading to a decrease in the electron density around the oxygen and in the double bond character of the $\mathrm{C}-\mathrm{O}$ bond, shifting the electron density in nitrogen from the non-bonding orbital to the $\pi$ orbital of the $\mathrm{C}-\mathrm{N}$ bond. A similar effect can also be seen in the theoretical calculations of the AEA conformers I and II, in which II displays interactions between the hydroxyl group and the lone pairs around the nitrogen, decreasing the lone pair electron density and the torsional barrier height in comparison to that predicted for $\mathbf{I}$.

Summarizing, CP-FTMW spectroscopy was used to determine the preferred threedimensional shape and the methyl-torsional barrier height of $\mathrm{N}$-acetylethanolamine. Comparisons with other acetamides demonstrated the direct relationships among the electron density around the nitrogen, the conformation of the methyl group, and the $\mathrm{V}_{3}$ barrier height. Substitution of the nitrogen atom with different attached groups affects the electronic distribution and the resulting stabilization of the syn position of the methyl group.

Acknowledgments. The research was partially funded by NSF grants CHE-0618740 (for spectrometer construction) and CHE-0960074 (for travel). We thank Dr. David W. Pratt at the University of Vermont for use of the spectrometer and for helpful discussions. 


\section{References.}

(1) Pauling, L. The Nature of the Chemical Bond Ithaca, NY, 1939 and 1960.

(2) Chakrabarti, P.; Dunitz, J. D. Helv. Chim. Acta 1982, 65, 1555.

(3) Hirota, E.; Sugisaki, R.; Nielsen, C. J.; Sørensen, G. O. J. Mol. Spectrosc. 1974, 49, 251.

(4) Kitano, M.; Kuchitsu, K. Bull. Chem. Soc. Jpn. 1974, 47.

(5) Kitano, M.; Kuchitsu, K. Bull. Chem. Soc. Jpn. 1974, 47.

(6) Kitano, M.; Kuchitsu, K. Bull. Chem. Soc. Jpn. 1973, 46.

(7) Kurland, R. J.; Bright Wilson Jr, E. J. Chem. Phys. 1957, 27, 585.

(8) Tyler, J. K.; Sheridan, J.; Costain, C. C. J. Mol. Spectrosc. 1972, 43, 248.

(9) Bates, W. W.; Hobbs, M. E. J. Am. Chem. Soc. 1951, 73, 2151.

(10) Phillips, W. D. J. Chem. Phys. 1955, 23, 1363.

(11) Stewart, W. E.; Siddall Iii, T. H. Chem. Rev. 1970, 70, 517.

(12) Plusquellic, D. F.; Pratt, D. W. J. Phys. Chem. A 2007, 111, 7391.

(13) Kannengießer, R.; Klahm, S.; Nguyen, H. V. L.; Lüchow, A.; Stahl, W. J. Chem. Phys. 2014, 141.

(14) Kannengießer, R.; Lach, M. J.; Stahl, W.; Nguyen, H. V. L. ChemPhysChem 2015, 16, 1906.

(15) Ohashi, N.; Hougen, J. T.; Suenram, R. D.; Lovas, F. J.; Kawashima, Y.; Fujitake, M.; Pyka, J. J. Mol. Spectrosc. 2004, 227, 28.

(16) Fujitake, M.; Kubota, Y.; Ohashi, N. J. Mol. Spectrosc. 2006, 236, 97.

(17) Suenram, R. D.; Golubiatnikov, G. Y.; Leonov, I. I.; Hougen, J. T.; Ortigoso, J.; Kleiner, I.; Fraser, G. T. J. Mol. Spectrosc. 2001, 208, 188.

(18) Brown, G. G.; Dian, B. C.; Douglass, K. O.; Geyer, S. M.; Shipman, S. T.; Pate, B. H. Rev. Sci. Instrum. 2008, 79, 053103.

(19) Bird, R. G.; Neill, J. L.; Alstadt, V. J.; Young, J. W.; Pate, B. H.; Pratt, D. W. J. Phys. Chem. A 2011, 115, 9392.

(20) Frisch, M. J.; Trucks, G. W.; Schlegel, H. B.; Scuseria, G. E.; Robb, M. A.; Cheeseman, J. R.; Montgomery, J. A. J.; Vreven, T.; Kudin, K. N.; Burant, J. C.; Millam, J. M.; Iyengar, S. S.; Tomasi, J.; Barone, V.; Mennucci, B.; Cossi, M.; Scalmani, G.; Rega, N.; Petersson, G. A.; Nakatsuji, H.; Hada, M.; Ehara, M.; Toyota, K.; Fukuda, R.; Hasegawa, J.; Ishida, M.; Nakajima, T.; Honda, Y.; Kitao, O.; Nakai, H.; Klene, M.; Li, X.; Knox, J. E.; Hratchian, H. P.; Cross, J. B.; Bakken, V.; Adamo, C.; Jaramillo, J.; Gomperts, R.; Stratmann, R. E.; Yazyev, O.; Austin, A. J.; Cammi, R.; Pomelli, C.; Ochterski, J. W.; Ayala, P. Y.; Morokuma, K.; Voth, G. A.; Salvador, P.; Dannenberg, J. J.; Zakrzewski, V. G.; Dapprich, S.; Daniels, A. D.; Strain, M. C.; Farkas, O.; Malick, D. K.; Rabuck, A. D.; Raghavachari, K.; Foresman, J. B.; Ortiz, J. V.; Cui, Q.; Baboul, A. G.; Clifford, S.; Cioslowski, J.; Stefanov, B. B.; Liu, G.; Liashenko, A.; Piskorz, P.; Komaromi, I.; Martin, R. L.; Fox, D. J.; Keith, T.; Al-Laham, M. A.; Peng, C. Y.; Nanayakkara, A.; Challacombe, M.; Gill, P. M. W.; Johnson, B.; Chen, W.; Wong, M. W.; Gonzalez, C.; Pople, J. A. 2004.

(21) Bailey, W. C. Chem. Phys. 2000, 252, 57.

(22) Plusquellic, D. F.; Suenram, R. D.; Mate, B.; Jensen, J. O.; Samuels, A. C. J. Chem. Phys. 2001, 115, 3057.

(23) Hartwig, H.; Dreizler, H. Z. Naturforsch. A. 1996, 51, 923.

(24) Kundu, T.; Pradhan, B.; Singh, B. P. J. Chem. Sci. 2002, 114, 623. 


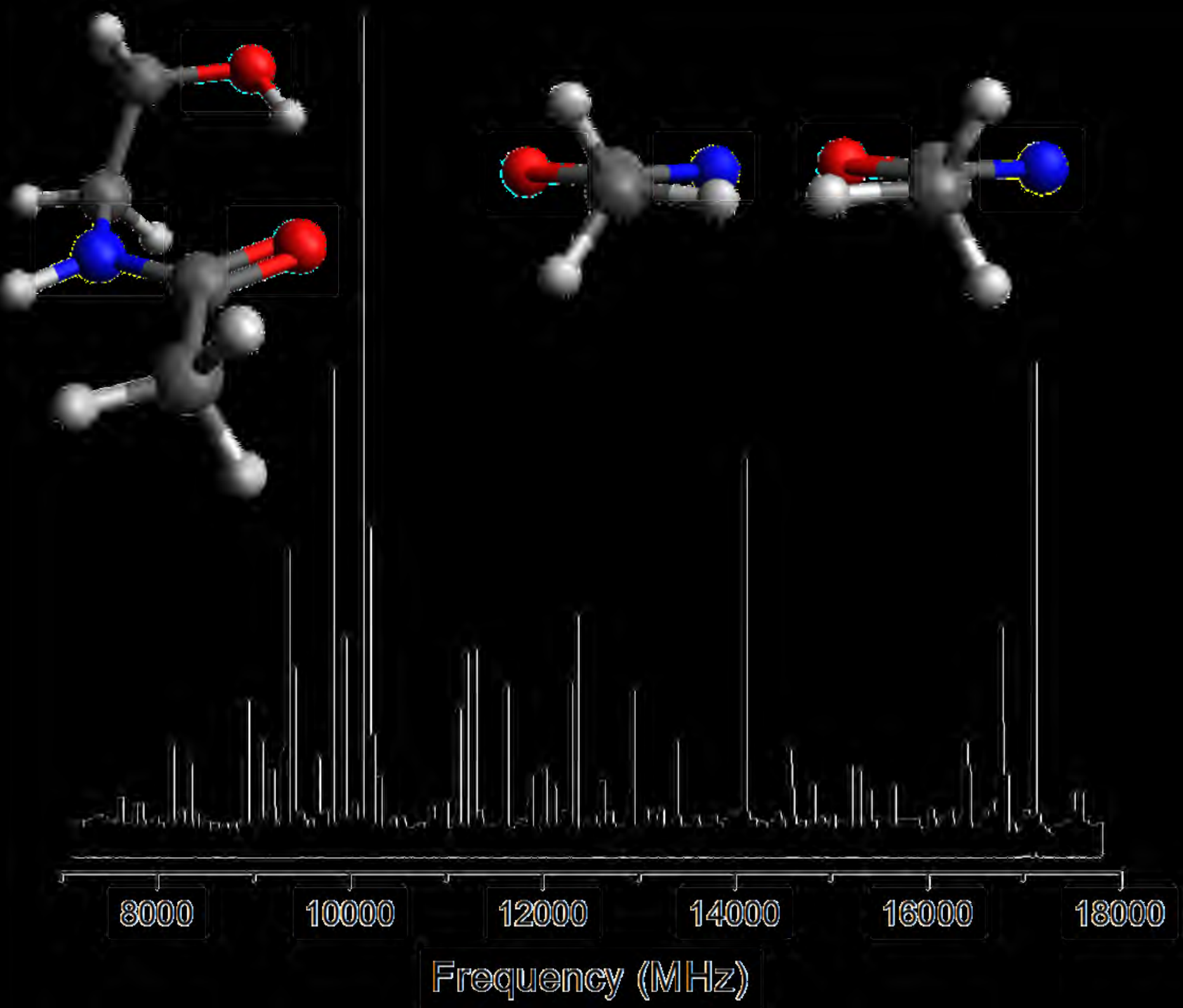

